\title{
Structural and biophysical properties of the integrin-associated cytoskeletal protein talin
}

\author{
Gordon C. K. Roberts • David R. Critchley
}

Received: 23 March 2009/Accepted: 23 April 2009 /Published online: 4 June 2009

(C) The Author(s) 2009. This article is published with open access at Springerlink.com

\begin{abstract}
Talin is a large cytoskeletal protein (2541 amino acid residues) which plays a key role in integrin-mediated events that are crucial for cell adhesion, migration, proliferation and survival. This review summarises recent work on the structure of talin and on some of the structurally better defined interactions with other proteins. The N-terminal talin head (approx. $50 \mathrm{kDa}$ ) consists of an atypical FERM domain linked to a long flexible rod (approx. $220 \mathrm{kDa}$ ) made up of a series of amphipathic helical bundle domains. The F3 FERM subdomain in the head binds the cytoplasmic tail of integrins, but this interaction can be inhibited by an interaction of F3 with a helical bundle in the talin rod, the so-called "autoinhibited form" of the molecule. The talin rod contains a second integrin-binding site, at least two actin-binding sites and a large number of binding sites for vinculin, which is important in reinforcing the initial integrin-actin link mediated by talin. The vinculin binding sites are defined by hydrophobic residues buried within helical bundles, and these must unfold to allow vinculin binding. Recent experiments suggest that this unfolding may be mediated by mechanical force exerted on the talin molecule by actomyosin contraction.
\end{abstract}

Keywords Cell adhesion · Extracellular matrix interactions . Integrin-actin link $\cdot$ Integrins $\cdot$ Talin

Electronic supplementary material The online version of this article (doi:10.1007/s12551-009-0009-4) contains supplementary material, which is available to authorized users.

G. C. K. Roberts $(\bowtie) \cdot$ D. R. Critchley

Department of Biochemistry, University of Leicester,

Henry Wellcome Building, Lancaster Road, PO Box 138,

Leicester LE1 9HN, UK

e-mail: gcr@le.ac.uk

\section{Introduction}

Integrins are a large family of cell-surface type 1 transmembrane adhesion receptors that mediate both cell-cell and cell-extracellular matrix (ECM) interactions. Integrins also have the unusual ability to support bidirectional signalling. Thus, the binding of integrins to the ECM potentiates the ability of growth factors to activate intracellular pathways that regulate cell proliferation, survival and migration ("outside-in signalling"), whilst the affinity of integrins for ECM proteins can be regulated from within the cell, the so-called "inside-out signalling" (Hynes 2002). Integrins are heterodimers of $\alpha$ and $\beta$ subunits, each containing a large extracellular domain (approx. 80$150 \mathrm{kDa}$ ), a single transmembrane $\alpha$-helix and a short, largely unstructured, cytoplasmic domain or "tail" of 10-70 residues. In mammals, one of $18 \alpha$-subunits interacts with one of eight $\beta$-subunits to form 24 distinct integrins, each with specific but overlapping functions (Hynes 2002). The current state of knowledge of integrins and integrin signalling is the topic of a recent special issue of the Journal of Cell Science (vol 122, issue 2, 2009).

Cell adhesion to the ECM is fundamental to the development of multi-cellular organisms and involves the coordinated assembly and disassembly of integrins into complexes called focal adhesions. In these complexes, the internal tails of integrin $\beta$-subunits are typically linked to the actin cytoskeleton via cytoplasmic proteins with scaffolding, adaptor, regulatory and mechanotransduction functions (Legate and Fassler 2009; Zaidel-Bar et al. 2007). An analysis of the proteins that are currently known to assemble into focal adhesions identified 90 core components physically located at adhesion sites (Zaidel-Bar et al. 2007), and 42 proteins have been identified that reportedly bind just to the cytoplasmic tails of $\beta$-integrins (Legate and 
Fassler 2009). Among these proteins, the cytoskeletal protein talin has been shown to play a pivotal role in integrinmediated events (Critchley 2009; Critchley and Gingras 2008). Talin promotes integrin clustering (Cluzel et al. 2005) and the switching of integrins from a low to high affinity state (Calderwood 2004; Harburger and Calderwood 2009; Tadokoro et al. 2003), although this also requires the kindlin family of proteins (Larjava et al. 2008). Talin also provides a direct link between integrins and the actin cytoskeleton (Jiang et al. 2003; Zhang et al. 2008) and acts as a scaffold for the recruitment of other proteins, such as vinculin (Ziegler et al. 2006). In this review we focus on recent studies of the structure and biophysics of talin, the results of which are beginning to throw light on the relationship between the structural and dynamic properties of this molecule and its function in the cell.

\section{The domain structure of talin}

There are two talin genes in vertebrates (Monkley et al. 2001; Senetar and McCann 2005). These code for talin1 and talin2, respectively, which are both large proteins (2541 amino acids; approx. $270 \mathrm{kDa}$ ) consisting of a globular Nterminal head (approx. $50 \mathrm{kDa}$ ) and a large flexible Cterminal rod (approx. $220 \mathrm{kDa}$ ) (Fig. 1). The talin head contains a FERM domain (residues 86-400) composed of F1, F2 and F3 domains. While initial attempts to crystallise the entire FERM domain have been unsuccessful to date, probably due to a large unstructured loop in F1 (Goult et al., in preparation), the crystal structure of the F2F3 fragment (Garcia-Alvarez et al. 2003) confirmed its structural similarity to the corresponding part of other FERM domains, with the F3 domain having a phosphotyr- osine binding (PTB)-like fold (Fig. 1). The 85 amino acids preceding F1 were initially ignored, but recent nuclear magnetic resonance (NMR) studies show that they constitute a folded domain, the F0 domain, which has a ubiquitinlike fold (Goult et al., in preparation) as does the F1 domain. The structure of an FOF1 double domain construct with the flexible F1 loop removed shows a well-defined and rather rigid interface between the two domains (Goult et al., in preparation) (Fig. 1).

The talin rod contains 62 helices that are organised into a series of helical bundles followed by a single Cterminal helix that forms an antiparallel homodimer (Gingras et al. 2008) (Fig. 1). Given the flexibility of the rod, the relative orientation of the two talin molecules within the dimer is uncertain. The rod starts with a fivehelix bundle (residues 482-655) (Papagrigoriou et al. 2004); the crystal structure of talin 482-789 shows that residues 656-789 form a four-helix bundle that packs tightly against the talin $482-655$ five-helix bundle in a staggered arrangement which is stabilised by an extensive hydrophobic interface (Papagrigoriou et al. 2004). The Cterminal half of the rod is also made up of a series of fivehelix bundles (Cheung et al. 2009; Gingras et al. 2006, 2008,2009; Goult et al. 2009), but in this region a relatively flexible interface and end-to-end packing between the helical bundles seems to be typical. The central part of the rod also contains four- and five-helix bundles, but their packing with respect to one another has not yet been established with certainty. Biophysical and electron microscopy (EM) studies suggest that talin exists in several different conformational states. Thus, sedimentation equilibrium experiments show that it can exist as both monomers and dimers (Molony et al. 1987). Sedimentation velocity, gel filtration and EM studies indicate that it

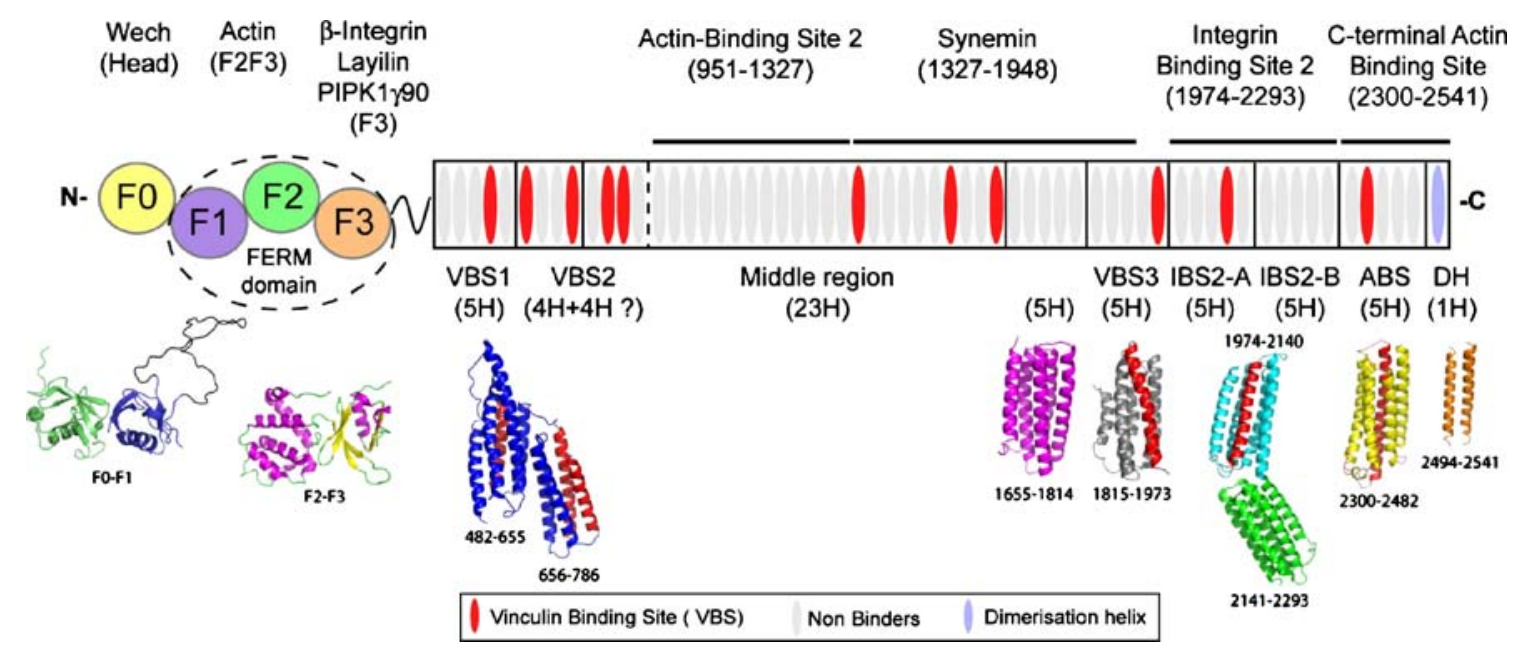

Fig. 1 Diagrammatic representation of the domain structure of talin, showing the location of the binding sites identified for other proteins, including integrins, actin and vinculin. Helices which bind vinculin are shown in red. Cartoon representations are shown for those domains whose structure has been determined (see text for references) 
is globular in low salt buffers, whereas it is a flexible elongated molecule (approx. $60 \mathrm{~nm}$ in length) in $0.15 \mathrm{M}$ salt and appears to have 10-12 globular domains (Molony et al. 1987; Winkler et al. 1997). The globular state appears to be dependent on a head/rod interaction, and recent data have provided insights into the structural basis of this interaction (Goksoy et al. 2008; Goult et al. 2009).

\section{Protein partners of talin}

The role of talin as an adaptor protein in linking integrins to the cytoskeleton and to signalling pathways in the cell is clearly indicated by the large number of proteins that have been shown to interact with talin (Critchley 2009; Critchley and Gingras 2008; Zaidel-Bar et al. 2007). Only a small number of the structurally better characterised interactions will be considered here.

The talin F3 FERM domain binds the cytoplasmic domains of $\beta$-integrin subunits (Calderwood et al. 2002) and the hyaluronan receptor layilin (Borowsky and Hynes 1998; Wegener et al. 2008) as well as the C-terminal region of PIPKI $\gamma 90$ (Barsukov et al. 2003; de Pereda et al. 2005; Di Paolo et al. 2002; Ling et al. 2002), a splice variant of phosphatidylinositol(4)- phosphate-5-kinase type $I \gamma$ which regulates the assembly of focal adhesions. The talin head also contains an F-actin binding site (Lee et al. 2004) and binds acidic phospholipids (e.g. Dietrich et al. 1993; Goldmann et al. 1995; Niggli et al. 1994).

The talin rod contains a second integrin binding site, IBS2 (Gingras et al. 2009; Moes et al. 2007; Rodius et al. 2008; Tremuth et al. 2004; Xing et al. 2001) and at least two actin-binding sites (Hemmings et al. 1996), the best characterised of which is at the C-terminus (Gingras et al. 2008; McCann and Craig 1997; Senetar et al. 2004; Smith and McCann 2007). Importantly, the rod also contains multiple binding sites for vinculin (Gingras et al. 2005), which itself has numerous binding partners, including Factin (Ziegler et al. 2006); the "cross-linking" of talin to actin by vinculin has been proposed to stabilise the initial weak integrin/talin/F-actin complexes (Bakolitsa et al. 2004).

\section{Integrin binding}

As noted above, the talin F3 domain has a PTB-like fold; canonical ligands of PTB domains are peptides containing an NPxY-like motif sequence. The short cytoplasmic tails of $\beta$-integrin subunits contain two such motifs, and the talin F3 FERM domain selectively binds to the membrane proximal to these, ${ }^{744} \mathrm{NPLY}^{747}$ (Campbell and Ginsberg 2004). The structure of F3 bound to residues ${ }^{739}$ WDTANN-
PLYDEA $^{750}$ of the $\beta 3$-integrin tail (Garcia-Alvarez et al. 2003) shows that the integrin peptide interacts predominantly with the hydrophobic surface on strand S5 of the F3 domain; W739 inserts into a pocket on the talin surface, with the subsequent residues forming a $\beta$-strand that extends the sheet formed by strands 5-7 of the F3 domain. Y747 projects into an acidic pocket in F3, whereas the equivalent region in those PTB domains that bind phosphotyrosine is strongly basic.

More recent studies have shown that F3 also interacts with the membrane-proximal helix of the $\beta 3$-tail; F727 and F730, which are on the same face of this helix, bind to a hydrophobic pocket in F3 made up of the flexible loop between $\beta$-strands 1 and 2 (Wegener et al. 2007). A mutation of either F727 or F730 in $\beta 3$-integrin, or of the interacting residues in F3 (notably L325), markedly reduced the activation of $\alpha \mathrm{IIb} \beta 3$ integrin (Wegener et al. 2007). These authors propose that talin F3 initially binds to $\beta 3$-integrin ${ }^{744} \mathrm{NPxY}^{747}$ and subsequently to the membrane-proximal helix, thereby breaking the salt bridge between the $\alpha$-and $\beta$-integrin tails which locks the integrin in a low affinity state. This hypothesis is supported by results from bimolecular fluorescence complementation studies in cells in which a talin L325R mutant was recruited to $\alpha \operatorname{IIb} \beta 3$-integrin tails but was unable to activate the integrin (Watanabe et al. 2008). However, talin F3 alone is not sufficient to activate $\beta 1$-integrins, and the F0 and F1 domains are also required (Bouaouina et al. 2008).

A variety of experiments indicate that the integrin binding sites in full-length talin are masked (Calderwood 2004; Martel et al. 2001), and recent NMR studies show that this is due to an interaction between the talin head and rod (Goksoy et al. 2008). Talin F3 was shown to bind to a talin rod fragment spanning residues 1654-2344, partially masking the binding site in F3 for the membrane-proximal helix of the $\beta 3$ integrin tail. This rod fragment contained higher affinity (residues 1654-1848) and lower affinity (residues 1984-2344) F3 binding sites. The domain boundaries of the region containing the high affinity site have now been defined structurally (Goult et al. 2009). The domain (residues 1655-1822) forms a five-helix bundle, and the positively charged integrin activation loop in F3 binds to a cluster of acidic residues, predominantly on helix 4 , masking the binding site for the $\beta 3$ integrin tail. The interaction is also expected to inhibit sterically the association of the talin FERM domain with the membrane. These results establish a structural basis for the "autoinihibited" form of talin. The mechanisms which disrupt this interaction to activate talin require further investigation, although the small GTPase Rap1 and its binding partner RIAM have been shown to play a key role in talin activation (Han et al. 2006; Lee et al. 2009; Watanabe et al. 2008), and PIPKI $\gamma 90$ and PIP2 have also been 
implicated (Goksoy et al. 2008; Ling et al. 2002; Ling et al. 2003; Martel et al. 2001).

There is evidence for a second integrin binding site (IBS2) towards the C-terminal end of the talin rod (Tremuth et al. 2004; Xing et al. 2001), which has been suggested to correspond to a single predicted helix (Moes et al. 2007; Rodius et al. 2008). A crystal structure has recently been reported for the region of the rod containing IBS2: mouse talin residues 1974-2293 (Gingras et al. 2009) comprises two five-helix bundles-"IBS2-A" (1974-2139) and "IBS2-B" (2140-2293) — connected by a continuous helix. The single helix previously identified as IBS2 corresponds to helix 4 in IBS2-A. However, tight integrin binding and targeting to focal adhesions appears to require both the IBS2-A and IBS2-B domains (Gingras et al. 2009), and it remains to be established exactly how this region of the rod binds to integrins.

\section{The C-terminal actin binding site in the rod}

Talin has binding sites for actin in the head (the F2F3 region) and in two distinct regions of the rod (Critchley 2009; Hemmings et al. 1996). The structure of the Cterminal actin binding site of talin1 (Gingras et al. 2008) comprises a five-helix bundle (residues 2300-2482), similar to the homologous region of the HIP1R protein (Brett et al. 2006); this domain is now referred to as a THATCH domain. The actin binding site maps to a conserved hydrophobic surface on helices 3 and 4 of the five-helix bundle that is flanked by basic residues. Interestingly, helix 1, which packs against the opposite face of the bundle, negatively regulates actin binding (Senetar et al. 2004). Deletion of this helix or the mutation of residues involved in its packing against the remainder of the bundle significantly increases actin binding (Gingras et al. 2008; Senetar et al. 2004), and there appear to be significant structural changes upon removal of the helix (Gingras et al. 2008).

The C-terminal helix of talin forms an antiparallel coiled-coil dimer (Gingras et al. 2008). F-actin only binds efficiently to the THATCH dimer, residues 2300-2541 (Gingras et al. 2008; Smith and McCann 2007), and residues on one face of the dimerisation helix may also contribute to actin binding (Gingras et al. 2008). SAXS experiments indicate that the THATCH dimer adopts an elongated structure in solution, and the high-resolution structures of the five-helix bundle and dimerisation domain can be readily modeled within the SAXS envelope. EM studies show that the THATCH dimer binds to three actin monomers along the long pitch of the same actin filament (Gingras et al. 2008); it does not crosslink F-actin-presumably, the actin-bundling activity of talin is explained by the presence of the other actin binding sites in talin.

\section{Binding of vinculin to the talin rod}

Vinculin is a $116-\mathrm{kDa}$ actin-binding protein that is localised in focal adhesions. It is made up of a globular head linked to a tail domain by a proline-rich region, and interaction sites for numerous binding partners have been mapped onto all three regions of the protein (Bakolitsa et al. 2004; Borgon et al. 2004; Ziegler et al. 2006). All of the wellcharacterised ligand-binding sites in vinculin (including that for talin) are masked by an intramolecular interaction between the vinculin head and tail domains (Bakolitsa et al. 2004; Borgon et al. 2004; Cohen et al. 2005; Izard et al. 2004; Johnson and Craig 1994, 1995a, b), and the molecule is thought to exist in an equilibrium between active and inactive states.

Initial studies identified at least three vinculin binding sites (VBSs) in the talin rod, and these were localised to three short peptide sequences (VBS1-3), each corresponding to a single predicted $\alpha$-helix (Bass et al. 1999). A systematic analysis of the binding of vinculin to peptides corresponding to each of the 62 helices of the rod revealed as many as 11 VBSs (Gingras et al. 2005), although it is clear that not all of these are available in the intact protein in vitro (Patel et al. 2006).

The talin-binding site in vinculin has been localised to residues 1-258 within the vinculin head (Bass et al. 2002), a helical domain (Vd1) which binds the vinculin tail $(\mathrm{Vt})$ with high affinity (Gilmore and Burridge 1996; Johnson and Craig 1994). Binding the talin VBS3 peptide induces a marked conformational change in $\mathrm{Vd} 1$ that displaces $\mathrm{Vt}$, and the VBS3 peptide itself sits in a hydrophobic groove formed predominantly by helices 1 and 2 of $\mathrm{Vd} 1$ (Izard et al. 2004). Similar results have been reported for Vdl in complex with other VBSs (Fillingham et al. 2005; Gingras et al. 2005; Papagrigoriou et al. 2004).

The structure of the N-terminal part of the talin rod (residues 482-655) shows that it consists of a 5-helix bundle in which helix 4 is equivalent to VBS1 (Papagrigoriou et al. 2004). The key vinculin-binding determinants are five hydrophobic residues (L608, A612, L615, V619 and L623) on one face of the VBS1 helix which are normally buried within the hydrophobic core of the five-helix bundle. Comparison of the structure of the Vd1/VBS1 complex with that of talin 482-655 shows that Vd1 helices 1-4 occupy the equivalent positions in relation to the VBS1 helix as do helices 1, 5, 2 and 3 in the talin 482-655 five-helix bundle, and key hydrophobic contacts are maintained by interactions with similar side chains in Vd1. Thus, the VBS1 helix (helix 4) is extracted 
from its own five-helix bundle and forms an equivalent five-helix bundle with the four helices of Vdl (Papagrigoriou et al. 2004) (Fig. 2).

This striking observation implies that the helical bundle of talin 482-655 must unfold to allow the vinculin binding sequence to bind in the hydrophobic groove of the vinculin head. While there are now many examples of proteins which are intrinsically disordered but which adopt a welldefined three-dimensional structure on binding to a protein or nucleic acid partner (e.g. Dyson and Wright 2005; Sugase et al. 2007), the observation of a protein which exists in a stable folded conformation but which must unfold in order to interact with a partner protein is much more unusual. Observations by a range of different biochemical and biophysical techniques have demonstrated this unusual "unfolding for binding" behaviour in VBScontaining constructs from different parts of the rod. These include:

- The talin 482-655 five-helix bundle binds Vd1 only weakly. Removal of the C-terminal helix destabilises the helical bundle and leads to the partial unfolding of the protein, as shown by NMR, yet this is accompanied by tighter binding to vinculin (Papagrigoriou et al. 2004).
- Talin $482-655$ is stable to proteolysis by trypsin, whereas the four-helix construct talin $482-636$ is readily degraded. In the complex of Vd1 with talin 482-636, Vd1 and the VBS1 sequence within the talin domain become stable to proteolysis, but all of the remaining talin helices are degraded (Papagrigoriou et al. 2004).

- In the $\left[{ }^{1} \mathrm{H},{ }^{15} \mathrm{~N}\right]-\mathrm{HSQC}$ NMR spectrum of the complex between Vd1 and ${ }^{15} \mathrm{~N}$-labeled talin 1843-1973, fewer cross-peaks are observed compared to the free protein, and these have a much smaller chemical shift dispersion. Cross-peaks which are not observed in the complex map onto helix $\mathrm{H} 4$ (the helix that binds vinculin), the $\mathrm{C}$-terminal half of helix $\mathrm{H} 3$, and a short stretch at the C-terminus of helix H1. The highest crosspeak intensities correspond to helix $\mathrm{H} 2$ and the Nterminal part of helix H3 (Gingras et al. 2006). This provides direct evidence for substantial conformational mobility of those parts of the talin domain which are not in contact with vinculin, and hence for the unfolding of the helical bundle. Similar observations were made with talin 755-889 (Fillingham et al. 2005).

- The talin 755-889 4-helix bundle has two threonine pairs (T775/T809 and T833/T867) within the hydro-
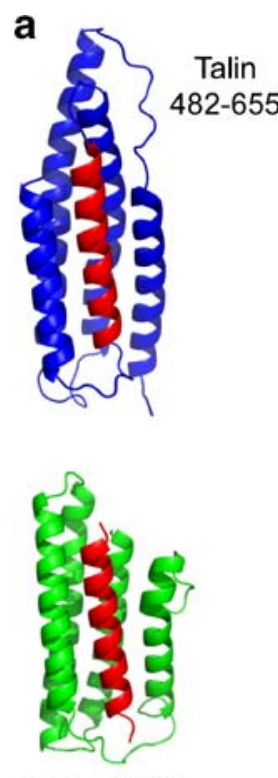

b
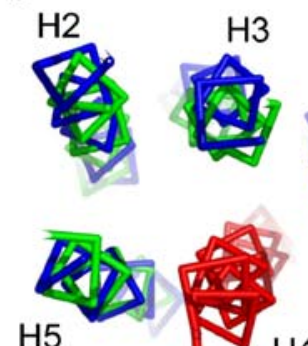

$\mathrm{H} 4$

(VBS1)
Vd1 - VBS1

Fig. 2 a Topological equivalence of vinculin binding site $(V B S) 1$ helix (red) within the talin 482-655 structure (blue) and the Vd1/ VBS1 complex structure (green). b End-on view of the superposed helices of talin 482-655 (blue) and the Vd1/VBS1 complex (green) with the VBS1 helix in red in each case. Data in $\mathbf{a}$ and $\mathbf{b}$ are from Papagrigoriou et al. (2004). c Electron paramagnetic resonance (EPR) spectra of spin-labelled talin 1843-1973. Top Room temperature (298 K) spectra of a sample spin-labelled at residue 1927. In the absence of $\mathrm{Vd} 1$ (black line), the line shape indicates a moderately mobile spin label with signs of tertiary interaction. After the addition

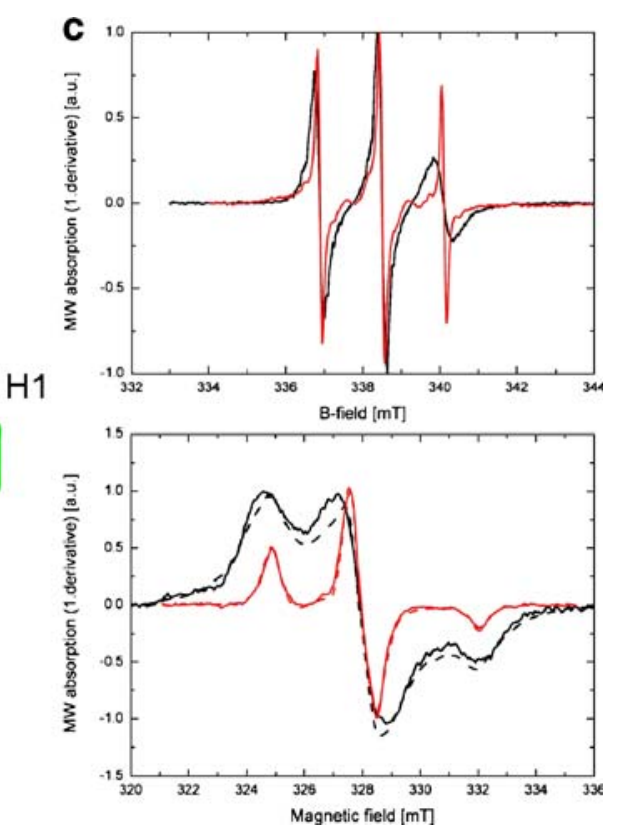

of $\mathrm{Vd} 1$, the mobility increases (red line), showing a line shape corresponding to an opened, disordered structure. Bottom Measured (solid) and calculated (dashed) low-temperature (155 K) spectra of a sample spin-labelled at residues 1887 and 1927 in the absence (black) and presence $(r e d)$ of $\mathrm{Vd} 1$. The theoretical spectra were calculated using a Gaussian distance distribution of $4.0 \AA$ and a mean distance of $<9 \AA$ in the first and $>20 \AA$ in the second case, indicating a dramatic increase of the distance between the two labeled positions on binding to Vd1. Data from Gingras et al. (2006) 
phobic core of the bundle (Fillingham et al. 2005). A mutant in which these were replaced by isoleucine/ valine pairs (T775V/T809I/T833I/T867V) was much more stable than the wild-type construct but bound Vd1 much more weakly (Patel et al. 2006).

- The effects of vinculin Vd1 binding on talin 1843-1973 have been studied by site-directed spin-labeling (Gingras et al. 2006). Cysteine residues were placed at key positions by mutagenesis; these were labeled with a nitroxide spin label to give singly or doubly spinlabeled proteins. Analysis of the EPR spectra to obtain information on the local mobility and on the distances between the nitroxides (Fig. 2) provided clear evidence that, on binding Vd1, the helical bundle unfolds as do at least two of the constituent helices, the VBS-containing helix 4 being immobilised in the complex.

\section{The activation of vinculin binding to talin}

The variations in the stability of the individual helical bundles that make up the talin rod are undoubtedly significant factors in determining vinculin binding. For the isolated domains, one could envisage either that the talin bundle is dynamic, and unfolds spontaneously to release the VBS which then binds to Vd1, or that an initial interaction of Vd1 with the folded talin bundle promotes unfolding of the latter. However, it is clear that the majority of the VBSs in intact talin are in a cryptic or low affinity state (Patel et al. 2006). Therefore, it appears that addition of vinculin is not in itself sufficient to lead to their activation.

Talin is required for the formation of the initial weak linkage between a fibronectin/integrin complex and actomyosin (Jiang et al. 2003), but reinforcement of this link by the recruitment of additional components is thought to be essential for focal adhesion assembly. Activation of the cryptic VBSs could increase the number of vinculin molecules bound simultaneously to talin and, because the vinculin tail binds F-actin (Ziegler et al. 2006), a progressive increase in vinculin binding to talin could provide a mechanism for a graduated strengthening of the link between integrins and the actin cytoskeleton. Since talin is clearly subject to the force exerted by actomyosin contraction and given that external mechanical force induces focal adhesion assembly (Galbraith et al. 2002), we have proposed that mechanical stretch may activate the VBSs in talin (Gingras et al. 2005; Papagrigoriou et al. 2004; Ziegler et al. 2006).

Direct evidence for this has recently come from elegant single molecule experiments on talin 482-889 reported by the Sheetz laboratory (del Rio et al. 2009). A construct containing residues $482-889$ with a His-tag at the Nterminus and a biotin tag at the $\mathrm{C}$-terminus was bound at one end to a Ni-NTA glass surface and at the other to an avidinated magnetic bead; the molecule could then be stretched by magnetic tweezers, and the binding of fluorescently labelled vinculin head detected by total internal reflection fluorescence (TIRF) microscopy. In the absence of mechanical force, binding of at most a single molecule of vinculin could be detected, which is consistent with earlier conclusions that many of the VBSs in this region are cryptic (Patel et al. 2006). However, the application of a force of $12 \mathrm{pN}$ to the talin led to a clear increase in the number of vinculin molecules bound, up to as many as three. Parallel force extension experiments showed mechanical unfolding of talin 482-889. These experiments demonstrate clearly that force-induced stretching can expose previously cryptic binding sites for vinculin in the N-terminal part of the talin rod (Fig. 3).

The pathway by which mechanical force unfolds talin bundles remains to be established, but recent steered molecular dynamics simulations on talin 482-889 (Hytonen and Vogel 2008) give an indication of the possibilities. The structure assumed for talin 482-889 was a five-helix bundle packed against a seven-helix bundle; this is a model
Fig. 3 Cartoon illustrating a possible mechanism for the activation of cryptic vinculin binding sites in the talin rod by mechanical stretch. For details see text. ECM Extracellular matrix

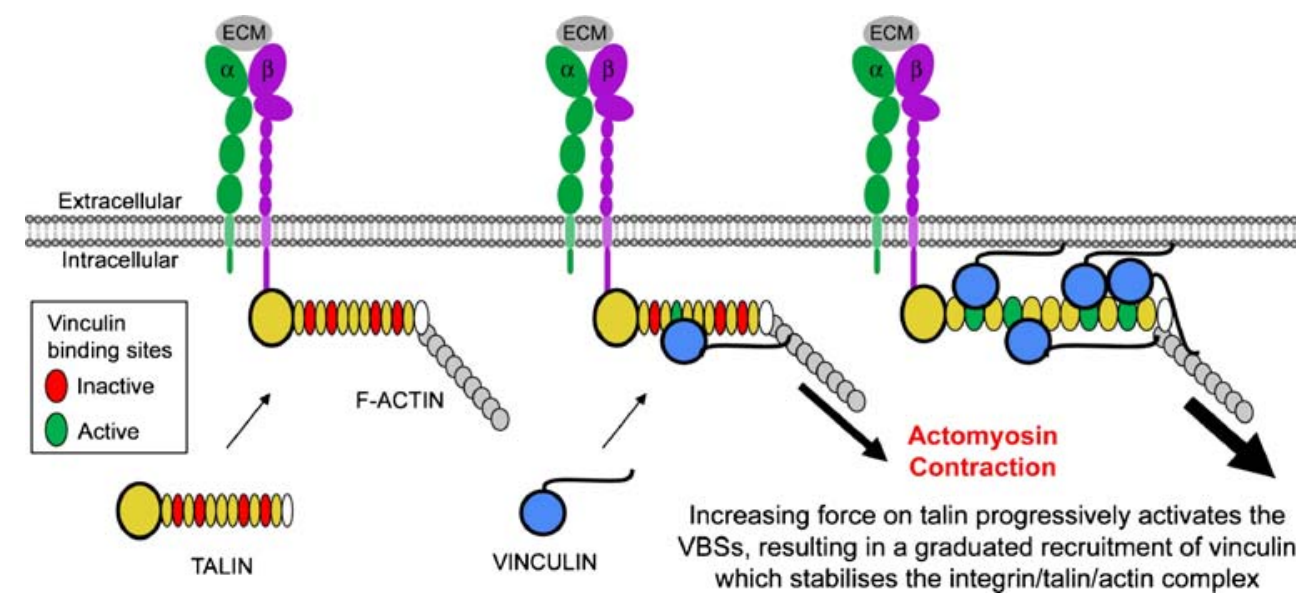


(Fillingham et al. 2005) rather than an experimental structure. Two kinds of simulation were carried out: one in which the force was applied to the $\mathrm{N}$ - and C-termini of the molecule and one in which it was applied laterally in a distributed fashion along the length of the two terminal helices. In both cases, the structure broke apart during the simulation into three components, comprising helices 1-5, 6-8 and 9-12. However, when the force was applied to the termini, this was preceded by the unraveling of helices 1 and 12 , followed by partial unraveling of helix 2 , so that at least one of the VBSs (helix 12) would be in a random coil state and would have to re-form its helical conformation to bind vinculin. The different behaviour according to the direction of the applied force is interesting and may imply different unfolding and activation mechanisms for VBSs within domains in different parts of the rod. In the $\mathrm{N}$ terminal region, where successive bundles pack closely against one another, the mechanical force is likely to act laterally on the helices, whereas in the C-terminal half of the rod, where the bundles have relatively flexible interfaces and end-to-end packing seems to be typical, the force would most probably act through the $\mathrm{N}$ - and $\mathrm{C}$ termini of each bundle.

\section{Conclusion}

It is clear that a picture of talin in which it binds at one end to integrin and at the other to actin is too simplistic. Both the talin head and rod contain binding sites for integrins and F-actin, although the significance of this remains to be established. Both the head and the rod also bind acidic phospholipids, and it will be important to establish whether the molecule lies along the cytoplasmic face of the membrane. It is also clear that talin exists in several conformational states (monomer/dimer and open and closed states). Much of talin exists in the cytoplasm in an autoinhibited form in which the talin rod masks the integrin binding site in the talin head, and the relative importance of the Rap1/ RIAM and PIPKI $\gamma 90 /$ PIP2 pathways in talin activation remain to be explored. Moreover, it has now been established from in vitro studies that the conformation of the talin rod is regulated by force, and it will be necessary to develop methods that allow this and the recruitment of vinculin to integrin/talin/actin complexes to be explored in real time and in a cellular context.

Acknowledgements We are most grateful to all of our colleagues and collaborators whose names appear in the references for their indispensable contributions to the work in our laboratory. We also thank Alex Gingras for his assistance with the figures. The work in our laboratory is currently supported by grants from the Wellcome
Trust, Cancer Research UK and the NIH Cell Migration Consortium (Grant U54 GM64346 from the National Institute of General Medical Sciences).

Open Access This article is distributed under the terms of the Creative Commons Attribution Noncommercial License which permits any noncommercial use, distribution, and reproduction in any medium, provided the original author(s) and source are credited.

\section{References}

Bakolitsa C, Cohen DM, Bankston LA, Bobkov AA, Cadwell GW, Jennings L, Critchley DR, Craig SW, Liddington RC (2004) Structural basis for vinculin activation at sites of cell adhesion. Nature 430:583-586. doi:10.1038/nature02610

Barsukov IL, Prescot A, Bate N, Patel B, Floyd DN, Bhanji N, Bagshaw CR, Letinic K, Di Paolo G, De Camilli P, Roberts GCK, Critchley DR (2003) Phosphatidylinositol phosphate kinase type $1 \gamma$ and $\beta 1$-integrin cytoplasmic domain bind to the same region in the talin FERM domain. J Biol Chem 278:3120231209. doi:10.1074/jbc.M303850200

Bass MD, Smith BJ, Prigent SA, Critchley DR (1999) Talin contains three similar vinculin-binding sites predicted to form an amphipathic helix. Biochem J 341:257-263. doi:10.1042/02646021:3410257

Bass MD, Patel B, Barsukov IG, Fillingham IJ, Mason R, Smith BJ, Bagshaw CR, Critchley DR (2002) Further characterization of the interaction between the cytoskeletal proteins talin and vinculin. Biochem J 362:761-768. doi:10.1042/02646021:3620761

Borgon RA, Vonrhein C, Bricogne G, Bois PR, Izard T (2004) Crystal structure of human vinculin. Structure 12:1189-1197. doi:10.1016/j.str.2004.05.009

Borowsky ML, Hynes RO (1998) Layilin, a novel talin-binding transmembrane protein homologous with C-type lectins, is localized in membrane ruffles. J Cell Biol 143:429-442. doi: $10.1083 /$ jcb.143.2.429

Bouaouina M, Lad Y, Calderwood DA (2008) The N-terminal domains of talin cooperate with the phosphotyrosine bindinglike domain to activate $\beta 1$ and $\beta 3$ integrins. J Biol Chem 283:6118-6125. doi:10.1074/jbc.M709527200

Brett TJ, Legendre-Guillemin V, McPherson PS, Fremont DH (2006) Structural definition of the F-actin-binding THATCH domain from HIP1R. Nat Struct Mol Biol 13:121-130. doi:10.1038/ nsmb1043

Calderwood DA (2004) Integrin activation. J Cell Sci 117:657-666. doi: $10.1242 /$ jes. 01014

Calderwood DA, Yan BX, de Pereda JM, Alvarez BG, Fujioka Y, Liddington RC, Ginsberg MH (2002) The phosphotyrosine binding-like domain of talin activates integrins. J Biol Chem 277:21749-21758. doi:10.1074/jbc.M111996200

Campbell ID, Ginsberg MH (2004) The talin-tail interaction places integrin activation on FERM ground. Trends Biochem Sci 29:429-435. doi:10.1016/j.tibs.2004.06.005

Cheung TYS, Fairchild MJ, Zarivach R, Tanentzapf G, van Petegem F (2009) Crystal structure of the talin integrin binding domain 2. J Mol Biol 387:787-793. doi:10.1016/j.jmb.2009.01.053

Cluzel C, Saltel F, Lussi J, Paulhe F, Imhof BA, Wehrle-Haller B (2005) The mechanisms and dynamics of $\alpha \mathrm{v} \beta 3$ integrin clustering in living cells. J Cell Biol 171:383-392. doi:10.1083/ jcb.200503017

Cohen DM, Chen H, Johnson RP, Choudhury B, Craig SW (2005) Two distinct head-tail interfaces cooperate to suppress activation 
of vinculin by talin. J Biol Chem 280:17109-17117. doi:10.1074/ jbc.M414704200

Critchley DR (2009) Biochemical and structural properties of the integrin-associated cytoskeletal protein talin. Annu Rev Biophys 38:235-254. doi:10.1146/annurev.biophys.050708.133744

Critchley DR, Gingras AR (2008) Talin at a glance. J Cell Sci 121:1345-1347. doi:10.1242/jcs.018085

de Pereda JM, Wegener KL, Santelli E, Bate N, Ginsberg MH, Critchley DR, Campbell ID, Liddington RC (2005) Structural basis for phosphatidylinositol phosphate kinase type $\mathrm{I} \gamma$ binding to talin at focal adhesions. J Biol Chem 280:8381-8386. doi:10.1074/jbc.M413180200

del Rio A, Perez-Jimenez R, Liu RC, Roca-Cusachs P, Fernandez JM, Sheetz MP (2009) Stretching single talin rod molecules activates vinculin binding. Science 323:638-641. doi:10.1126/science. 1162912

Di Paolo G, Pellegrini L, Letinic K, Cestra G, Zoncu R, Voronov S, Chang S, Guo J, Wenk MR, De Camilli P (2002) Recruitment and regulation of phosphatidylinositol phosphate kinase type $1 \gamma$ by the FERM domain of talin. Nature 420:85-89. doi:10.1038/ nature 01147

Dietrich C, Goldmann WH, Sackmann E, Isenberg G (1993) Interaction of NBD-talin with lipid monolayers - a film balance study. FEBS Lett 324:37-40. doi:10.1016/0014-5793(93) 81527-7

Dyson HJ, Wright PE (2005) Intrinsically unstructured proteins and their functions. Nat Rev Mol Cell Biol 6:197-208. doi:10.1038/ nrm1589

Fillingham I, Gingras AR, Papagrigoriou E, Patel B, Emsley J, Critchley DR, Roberts GC, Barsukov IL (2005) A vinculin binding domain from the talin rod unfolds to form a complex with the vinculin head. Structure 13:65-74. doi:10.1016/j. str.2004.11.006

Galbraith CG, Yamada KM, Sheetz MP (2002) The relationship between force and focal complex development. J Cell Biol 159:695-705. doi:10.1083/jcb.200204153

Garcia-Alvarez B, de Pereda JM, Calderwood DA, Ulmer TS, Critchley D, Campbell ID, Ginsberg MH, Liddington RC (2003) Structural determinants of integrin recognition by talin. Mol Cell 11:49-58. doi:10.1016/S1097-2765(02) 00823-7

Gilmore AP, Burridge K (1996) Regulation of vinculin binding to talin and actin by phosphatidyl-inositol-4, 5-bisphosphate. Nature 381:531-535. doi:10.1038/381531a0

Gingras AR, Ziegler WH, Frank R, Barsukov IL, Roberts GCK, Critchley DR, Emsley J (2005) Mapping and consensus sequence identification for multiple vinculin binding sites within the talin rod. J Biol Chem 280:37217-37224. doi:10.1074/jbc. M508060200

Gingras AR, Vogel KP, Steinhoff HJ, Ziegler WH, Patel B, Emsley J, Critchley DR, Roberts GCK, Barsukov IL (2006) Structural and dynamic characterization of a vinculin binding site in the talin rod. Biochemistry 45:1805-1817. doi:10.1021/bi0521361

Gingras AR, Bate N, Goult BT, Hazelwood L, Canestrelli I, Grossmann JG, Liu H, Putz NSM, Roberts GCK, Volkmann N, Hanein D, Barsukov IL, Critchley DR (2008) The structure of the C-terminal actin-binding domain of talin. EMBO J 27:458-469. doi:10.1038/sj.emboj. 7601965

Gingras AR, Ziegler WH, Bobkov AA, Joyce MG, Fasci D, Himmel M, Rothemund S, Ritter A, Grossmann JG, Patel B, Bate N, Goult BT, Emsley J, Barsukov IL, Roberts GCK, Liddington RC, Ginsberg MH, Critchley DR (2009) Structural determinants of integrin-binding to the talin rod. J Biol Chem (in press). doi:10.1074/jbc.M805937200

Goksoy E, Ma YQ, Wang XX, Kong XM, Perera D, Plow EF, Qin J (2008) Structural basis for the autoinhibition of talin in regulating integrin activation. Mol Cell 31:124-133. doi:10.1016/j.molcel.2008.06.011
Goldmann WH, Senger R, Kaufmann S, Isenberg G (1995) Determination of the affinity of talin and vinculin to charged lipid vesicles: a light scattering study. FEBS Lett 368:516-518. doi:10.1016/0014-5793(95) 00678-3

Goult BT, Bate N, Anthis NJ, Wegener KL, Gingras AR, Patel B, Barsukov IL, Campbell ID, Roberts GCK, Critchley DR (2009) The structure of an interdomain complex which regulates talin activity. J Biol Chem (in press). doi:10.1074/jbc.M900078200

Han JW, Lim CJ, Watanabe N, Soriani A, Ratnikov B, Calderwood DA, Puzon-McLaughlin W, Lafuente EM, Boussiotis VA, Shattil SJ, Ginsberg MH (2006) Reconstructing and deconstructing agonist-induced activation of integrin $\alpha \operatorname{IIb} \beta 3$. Curr Biol 16:1796-1806. doi:10.1016/j.cub.2006.08.035

Harburger DS, Calderwood DA (2009) Integrin signalling at a glance. J Cell Sci 122:159-163. doi:10.1242/jcs.018093

Hemmings L, Rees DJG, Ohanian V, Bolton SJ, Gilmore AP, Patel B, Priddle H, Trevithick JE, Hynes RO, Critchley DR (1996) Talin contains three actin-binding sites each of which is adjacent to a vinculin-binding site. J Cell Sci 109:2715-2726

Hynes RO (2002) Integrins: Bidirectional, allosteric signaling machines. Cell 110:673-687. doi:10.1016/S0092-8674(02) 00971-6

Hytonen VP, Vogel V (2008) How force might activate talin's vinculin binding sites: SMD reveals a structural mechanism. PLOS Comput Biol 4. doi:10.1371/journal.pcbi.0040024

Izard T, Evans G, Borgon RA, Rush CL, Bricogne G, Bois PRJ (2004) Vinculin activation by talin through helical bundle conversion. Nature 427:171-175. doi:10.1038/nature02281

Jiang GY, Giannone G, Critchley DR, Fukumoto E, Sheetz MP (2003) Two-piconewton slip bond between fibronectin and the cytoskeleton depends on talin. Nature 424:334-337. doi:10.1038/nature 01805

Johnson RP, Craig SW (1994) An intramolecular association between the head and tail domains of vinculin modulates talin binding. J Biol Chem 269:12611-12619

Johnson RP, Craig SW (1995a) The carboxy-terminal tail domain of vinculin contains a cryptic binding site for acidic phospholipids. Biochem Biophys Res Commun 210:159-164. doi:10.1006/ bbrc. 1995.1641

Johnson RP, Craig SW (1995b) F-actin binding site masked by the intramolecular association of vinculin head and tail domains. Nature 373:261-264. doi:10.1038/373261a0

Larjava H, Plow EF, Wu C (2008) Kindlins: essential regulators of integrin signalling and cell-matrix adhesion. EMBO Rep 9:12031208. doi:10.1038/embor.2008.202

Lee HS, Bellin RM, Walker DL, Patel B, Powers P, Liu HJ, GarciaAlvarez B, de Pereda JM, Liddington RC, Volkmann N, Hanein D, Critchley DR, Robson RM (2004) Characterization of an actin-binding site within the talin FERM domain. J Mol Biol 343:771-784. doi:10.1016/j.jmb.2004.08.069

Lee HS, Lim CJ, Puzon-McLaughlin W, Shattil SJ, Ginsberg MH (2009) RIAM activates integrins by linking talin to RAS GTPase membrane-targeting sequences. J Biol Chem 284:5119-5127. doi:10.1074/jbc.M807117200

Legate KR, Fassler R (2009) Mechanisms that regulate adaptor binding to beta-integrin cytoplasmic tails. J Cell Sci 122:187198. doi: $10.1242 /$ jes. 041624

Ling K, Doughman RL, Firestone AJ, Bunce MW, Anderson RA (2002) Type I $\gamma$ phosphatidylinositol phosphate kinase targets and regulates focal adhesions. Nature 420:89-93. doi:10.1038/nature 01082

Ling K, Doughman RL, Iyer VV, Firestone AJ, Bairstow SF, Mosher DF, Schaller MD, Anderson RA (2003) Tyrosine phosphorylation of type $\mathrm{I} \gamma$ phosphatidylinositol phosphate kinase by src regulates an integrin-talin switch. J Cell Biol 163:1339-1349. doi:10.1083/ jcb.200310067 
Martel V, Racaud-Sultan C, Dupe S, Marie C, Paulhe F, Galmiche A, Block MR, Albiges-Rizo C (2001) Conformation, localization, and integrin binding of talin depend on its interaction with phosphoinositides. J Biol Chem 276:21217-21227. doi:10.1074/ jbc.M102373200

McCann RO, Craig SW (1997) The I/LWEQ module: A conserved sequence that signifies F-actin binding in functionally diverse proteins from yeast to mammals. Proc Natl Acad Sci USA 94:5679-5684. doi:10.1073/pnas.94.11.5679

Moes M, Rodius S, Coleman SJ, Monkley SJ, Goormaghtigh E, Tremuth L, Kox C, van der Holst PPG, Critchley DR, Kieffer $\mathrm{N}$ (2007) The integrin binding site 2 (IBS2) in the talin rod domain is essential for linking integrin $\beta$ subunits to the cytoskeleton. J Biol Chem 282:17280-17288. doi:10.1074/jbc. M611846200

Molony L, McCaslin D, Abernethy J, Paschal B, Burridge K (1987) Properties of talin from chicken gizzard smooth muscle. J Biol Chem 262:7790-7795

Monkley SJ, Pritchard CA, Critchley DR (2001) Analysis of the mammalian talin2 gene TLN2. Biochem Biophys Res Commun 286:880-885. doi:10.1006/bbrc.2001.5497

Niggli V, Kaufmann S, Goldmann WH, Weber T, Isenberg G (1994) Identification of functional domains in the cytoskeletal protein talin. Eur J Biochem 224:951-957. doi:10.1111/j.1432-1033.1994.00951.x

Papagrigoriou E, Gingras AR, Barsukov IL, Bate N, Fillingham IJ, Patel B, Frank R, Ziegler WH, Roberts GCK, Critchley DR, Emsley J (2004) Activation of a vinculin-binding site in the talin rod involves rearrangement of a five-helix bundle. EMBO J 23:2942-2951. doi:10.1038/sj.emboj.7600285

Patel B, Gingras AR, Bobkov AA, Fujimoto LM, Zhang M, Liddington RC, Mazzeo D, Emsley J, Roberts GCK, Barsukov IL, Critchley DR (2006) The activity of the vinculin binding sites in talin is influenced by the stability of the helical bundles that make up the talin rod. J Biol Chem 281:7458-7467. doi:10.1074/jbc.M508058200

Rodius S, Chaloin O, Moes M, Schaffner-Reckinger E, Landrieu I, Lippens G, Lin MH, Zhang J, Kieffer N (2008) The talin rod IBS2 $\alpha$-helix interacts with the $\beta 3$ integrin cytoplasmic tail membrane-proximal helix by establishing charge complementary salt bridges. J Biol Chem 283:24212-24223. doi:10.1074/jbc.M709704200

Senetar MA, Foster SJ, McCann RO (2004) Intrasteric inhibition mediates the interaction of the I/LWEQ module proteins talin1, talin2, Hip1, and Hip12 with actin. Biochemistry 43:1541815428. doi:10.1021/bi0487239

Senetar MA, McCann RO (2005) Gene duplication and functional divergence during evolution of the cytoskeletal linker protein talin. Gene 362:141-152. doi:10.1016/j.gene.2005.08.012
Smith SJ, McCann R (2007) A C-terminal dimerization motif is required for focal adhesion targeting of talin 1 and the interaction of the talin $1 \mathrm{I} / \mathrm{LWEQ}$ module with F-actin. Biochemistry 46:10886-10898. doi:10.1021/bi700637a

Sugase K, Dyson HJ, Wright PE (2007) Mechanism of coupled folding and binding of an intrinsically disordered protein. Nature 447:1021-1023. doi:10.1038/nature05858

Tadokoro S, Shattil SJ, Eto K, Tai V, Liddington RC, de Pereda JM, Ginsberg MH, Calderwood DA (2003) Talin binding to integrin beta tails: A final common step in integrin activation. Science 302:103-106. doi:10.1126/science.1086652

Tremuth L, Kreis S, Melchior C, Hoebeke J, Ronde P, Plancon S, Takeda K, Kieffer N (2004) A fluorescence cell biology approach to map the second integrin-binding site of talin to a 130 -amino acid sequence within the rod domain. J Biol Chem 279:2225822266. doi:10.1074/jbc.M400947200

Watanabe N, Bodin L, Pandey M, Krause M, Coughlin S, Boussiotis VA, Ginsberg MH, Shattil SJ (2008) Mechanisms and consequences of agonist-induced talin recruitment to platelet integrin LIIbß3. J Cell Biol 181:1211-1222. doi:10.1083/jcb.200803094

Wegener KL, Partridge AW, Han J, Pickford AR, Liddington RC, Ginsberg MH, Campbell ID (2007) Structural basis of integrin activation by talin. Cell 128:171-182. doi:10.1016/j. cell.2006.10.048

Wegener KL, Basran J, Bagshaw CR, Campbell ID, Roberts GCK, Critchley DR, Barsukov IL (2008) Structural basis for the interaction between the cytoplasmic domain of the hyaluronate receptor layilin and the talin F3 subdomain. J Mol Biol 382:112126. doi:10.1016/j.jmb.2008.06.087

Winkler J, Lunsdorf H, Jockusch BM (1997) Energy-filtered electron microscopy reveals that talin is a highly flexible protein composed of a series of globular domains. Eur J Biochem 243:430-436. doi:10.1111/j.1432-1033.1997.0430a.x

Xing BD, Jedsadayanmata A, Lam SCT (2001) Localization of an integrin binding site to the $\mathrm{C}$ terminus of talin. $\mathrm{J}$ Biol Chem 276:44373-44378. doi:10.1074/jbc.M108587200

Zaidel-Bar R, Itzkovitz S, Ma'ayan A, Iyengar R, Geiger B (2007) Functional atlas of the integrin adhesome. Nat Cell Biol 9:858867. doi: $10.1038 / \mathrm{ncb} 0807-858$

Zhang X, Jiang G, Cai Y, Monkley SJ, Critchley DR, Sheetz MP (2008) Talin depletion reveals independence of initial cell spreading from integrin activation and traction. Nat Cell Biol 10:1062-1068. doi:10.1038/ncb1765

Ziegler WH, Liddington RC, Critchley DR (2006) The structure and regulation of vinculin. Trends Cell Biol 16:453-460. doi:10.1016/j.tcb.2006.07.004 